Research Paper

\title{
APPLICATION OF SERVIR - MEKONG'S RDCYIS TOOL TO EN- HANCE DROUGHT FORECAST AND WARNING GENERATION IN NINH THUAN PROVINCE
}

\author{
Dang Thanh Binh¹, Ha Hai Duong², Nguyen Minh Tien², Nguyen Hanh Quyen ${ }^{3}$, Susantha \\ Jayasingh $^{3}$
}

\section{ARTICLE HISTORY}

Received: February 08, 2020 Accepted: April 19, 2020

Publish on: April 25, 2020

\begin{abstract}
As considered as a hotspot of drought in Vietnam, Ninh Thuan in recent years has to face with 10 years repetition of severe droughts which captured in 1993-1994; 2004-2005 2014-2016 and 2019-2020. Under the pressure of population growth, increasing water demand for economic sectors, and the context of climate change, drought influences and its occurrences are more and more fierce and complex. Therefore, the research and application of advanced technology as Regional Drought and Crop Yield Information System (RDCYIS) developed by Asian Disaster Preparedness Center (ADPC) on drought assessment and forecast to the local is considered as a proper selection. In this research, Standardized Precipitation Index (SPI) 1 month and 3 months generated by RDCYIS was used and compared with that of 3 selected in-situ stations in Ninh Thuan province. The results shown that the determination of the historical rainfall at any location by RDCYIS is convenient, overcoming the disadvantage of the lack of rain measuring station in the past. This would help to prepare for and respond to drought situations impacted
\end{abstract}

due to climate change by taking short and longterm risk mitigation measures such as accurate water management in reservoirs and adjusting cropping calendars, and so on. As such, tool performance in improving drought bulletins and management strategies in Ninh Thuan province is detailed in this paper.

Keywords: RDCYIS, drought indices, risk mitigation.

\section{Introduction}

Ninh Thuan is the region with the scarcest surface water in the country, with an average annual rainfall of about $1,100 \mathrm{~mm}$ throughout the province. The rainfall itself is not distributed evenly over time and space. While the upstream area of Cai Phan Rang River has a rainfall of about $2,000 \mathrm{~mm}$, the coastal area is only approximately $700 \mathrm{~mm}$. Every year, Ninh Thuan is affected by natural disasters due to drought, water shortage and intrusion (Ninh Thuan Hydro-met centre, 2019b).

The drought situation in recent years in Ninh Thuan is more severe and complex, typically

$\triangle$ DANG THANH BINH

Corresponding author: Phuthuanthien030@gmail.com

${ }^{1}$ Meteorology and Hydrological center in south central region;

${ }^{2}$ Vietnam Academy of Water Resources

${ }^{3}$ Asian Disaster Preparedness Center 
from 1993-1994, 2004-2005, 2014-2016, and 2019-2020 (Sam, 2008; Sam and Vuong, 2008). Severe drought is often repeated after 10 years. Recently, the water level in rivers, streams, ponds and lakes in the province is increasingly exhausted, causing great losses to farmers agriculture production and daily life (Ninh Thuan Hydro-met centre, 2019a; Ninh Thuan IMC, 2019; Binh, 2016). In the context of climate change, drought and natural disasters are increasingly fierce, the research and application of advanced technology for drought forecast and monitoring is really urgent.

As a supportive decision-maker, SERVIR Mekong's Regional Drought Information and Crop Productivity System (RDCYIS: https://rdcyis-servir.adpc.net/map) can help to find the necessary measures to prevent, monitor and forecast drought as well as providing information on yields for a number of crops along with assessments of socio-economic and environmental im- pacts in countries in the lower Mekong region, including Ninh Thuan province, Vietnam. The product is supported by the United States Agency for International Development (USAID); US Aerospace Agency (NASA); Asian Disaster Preparedness Center (ADPC); Vietnam Academy of Water Resources (VAWR).

The RDCYIS deploys the Regional Hydrologic Extreme Assessment System (RHEAS) that is an integration of hydrological and crop simulation models developed by NASA-Jet Propulsion Laboratory. The core of the RHEAS framework is the Variable Infiltration Capacity (VIC) model and the Decision Support System for Agro-Technology Transfer (DSSAT) model that automates the deployment of nowcasting and forecasting hydrologic simulations and ingests satellite observations through data assimilation (Fig. 1).

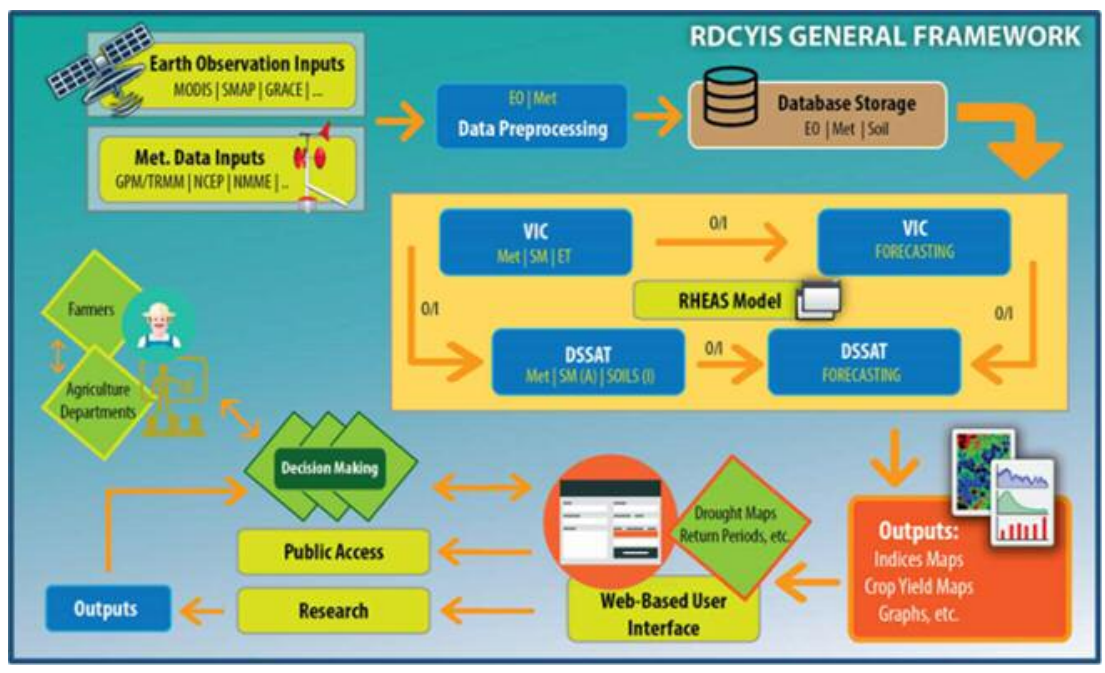

Fig. 1. General Framework of RDCYIS

It also allows coupling of other environmental models and facilitates the delivery of data products to users via a GIS enabled database. The system's ability to carry our nowcast and forecast within the framework at the same time gives an upper edge to the present existing resources or systems available for drought monitoring. A variety of drought indicators which are suitable for meteorological, agricultural and hy- drological droughts such as Combined Drought Index (CDI), Standardized Precipitation Index (SPI $(1,3,6,12))$, Standardized Runoff Index (SRI $(1,3,6,12))$, Soil Moisture Deficit Index (SMDI), Dry Spells, Root Zone Soil Moisture (RZSM) and Drought Severity as well as soil variables, energy balance variables and water balance variables are also available in the system for public access (Fig. 2). 


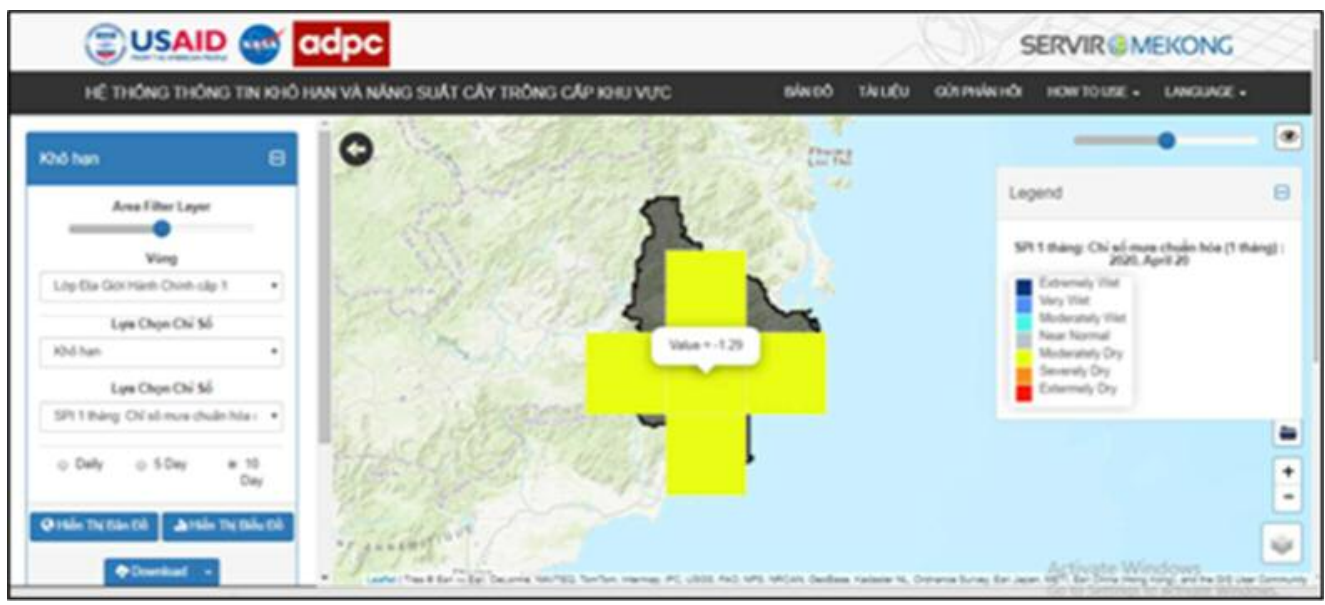

Fig. 2. Map interface of the RDCYIS

The aim of this research is applied RDCYIS to generate drought data, and assess these data with insitu data. Accordingly, the warning and forecasting of drought for Ninh Thuan is recommended by 6-month toward.

\section{Methodology}

\subsection{Study Area}

Ninh Thuan province is in the middle of Central Vietnam, with a small plain area created by the Dinh River which is originated from Lam
Vien Plateau (Fig. 3). The climate is a combination of the tropical monsoon and dry and windy weather. It is hot, dry and windy all over the year. There are two seasons: the rainy season lasts from May to November, the dry season lasts from December to April. Annual average temperature is $27^{\circ} \mathrm{C}$. Frequent prolonged heatwaves in the southern central province of Ninh Thuan over the dry season has led to drought, forcing many localities to suspend plant and animal farming.

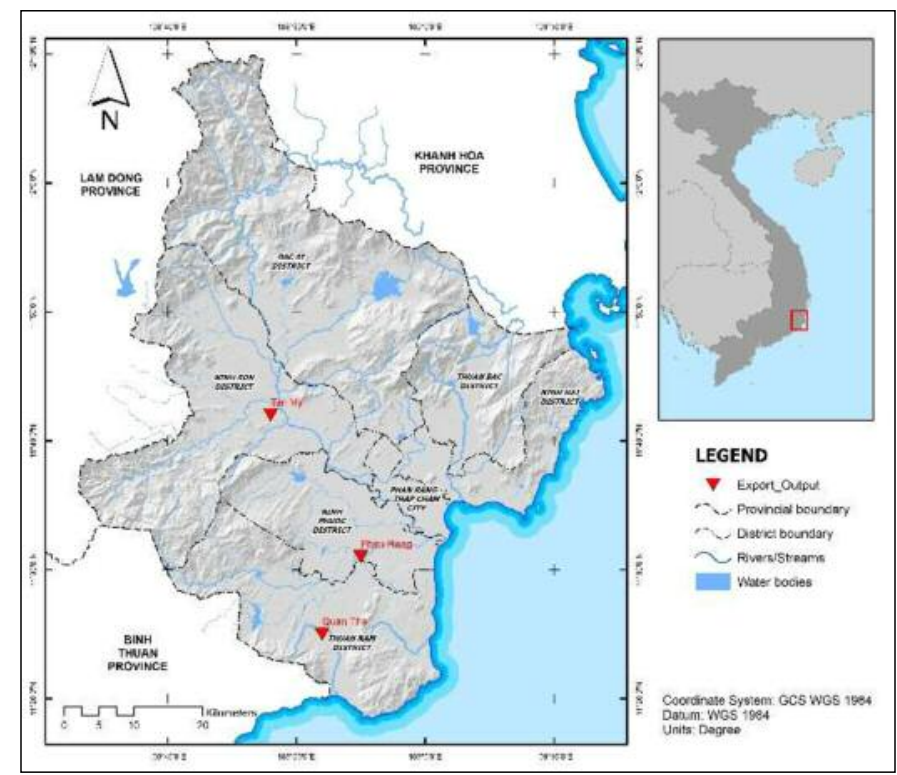

Fig. 3. Map of NinhThuan Province and location of selected rainfall stations

\subsection{Data used}

Data from three ground rainfall stations, namely Phan Rang, Quan The and Tan My sta- tion in Ninh Thuan province for the period 19812018 has been utilized for this study (Fig. 3). Apply the SPI 1 formula of McKee and Edwards 
(1997) for these in-situ data in excel calculation, the SPI 1 month result for each station has been calculated and displayed in Table 3 to Table 5.

Standardized Precipitation Index (SPI) 1 month and 3 months data products available in RDCYIS for the 1981-2018 period utilized in this study. This data is available in GeoTIFF format.

\subsection{Review of the Standardized Precipita-} tion Index (SPI) at some specific rainfall station

\subsubsection{Theoretical of calculating SPI}

a) The transformation of the precipitation value in to standardized precipitation index has the purpose of:

(i) Transforming the mean of the precipitation value adjusted to 0 ;

(ii) Standard deviation of the precipitation is adjusted to 1.0;

(iii) Skewness of the existing data has to be readjusted to zero.

When these goals have been achieved the standardized precipitation index can be interpreted as mean 0 and standard deviation of 1.0.

b) Mean of the precipitation can be computed as:

$$
\bar{X}=\frac{\sum X}{n}
$$

c) The standard deviation for the precipitation is computed as:

$$
\sigma=\sqrt{\frac{\sum(X-\bar{X})^{2}}{n}}
$$

d) The skewness of the given precipitation is computed as:

$$
\text { Skew }=\frac{n}{(n-1)(n-2)} \sum\left(\frac{X-\bar{X}}{\sigma}\right)^{3}
$$

e) The precipitation is converted to lognormal values and the statistics $U$, shape and scale parameters of Gamma distribution is computed.

$$
\begin{gathered}
\bar{X}_{l n}=\ln (\bar{X}) \\
U=\ln (\bar{X})-\frac{\sum \ln (X)}{n} \\
\text { scaleparameter }=\alpha=\frac{1+\sqrt{1+\frac{4 U}{3}}}{4 U}
\end{gathered}
$$

$$
\text { shapeparameter }=\beta=\frac{\bar{X}}{\alpha}
$$

where $\mathrm{n}$ is the number of precipitation observations; $\mathrm{X}$ is observed precipitation $(\mathrm{mm}) ; \bar{X}$ is mean of the precipitation which calculated by equation [1]; $\sigma$ is skewness of the given precipitation which calculated by equation [2]; $\mathrm{U}$ is statistis; $\alpha$ and $\beta$ are scale and shape parameters respectively.

The resulting parameters are then used to find the cumulative probability of an observed precipitation event. The cumulative probability is given by:

$$
G(x)=\frac{\int_{0}^{x} x^{a-1} e^{\frac{-x}{\beta}} d x}{\beta^{\alpha} \mathrm{T}(\alpha)}
$$

Since the gamma function is undefined for $\mathrm{x}=0$ and a precipitation distribution may contain zeros, the cumulative probability becomes:

$$
H(x)=q+(1-q) G(x)
$$

where $\mathrm{q}$ is the probability of zero.

The cumulative probability $\mathrm{H}(\mathrm{x})$ is then transformed to the standard normal random variable $\mathrm{Z}$ with mean zero and variance of one, which is the value of the SPI following Edwards and McKee (1997); we employ the approximate conversion provided by Abromowitz and Stegun (1965) as an alternative.

$$
\begin{gathered}
Z=S P I=-\left(t-\frac{c_{0}+c_{1} t+c_{2} t^{2}}{1+d_{1} t+d_{2} t^{2}+d_{3} t^{3}}\right) \\
0<H(x) \leq 0.5 \\
Z=S P I=+\left(t-\frac{c_{0}+c_{1} t+c_{2} t^{2}}{1+d_{1} t+d_{2} t^{2}+d_{3} t^{3}}\right) \\
0.5<H(x) \leq 1
\end{gathered}
$$

where

$$
\begin{gathered}
t=\sqrt{\ln \left(\frac{1}{H(x)^{2}}\right)} \quad 0<H(x) \leq 0.5 \\
t=\sqrt{\ln \left(\frac{1}{(1-H(x))^{2}}\right)} \quad 0.5<H(x) \leq 1 \\
c_{0}=2.515517 \\
c_{1}=0.802583 \\
c_{2}=0.010328 \\
d_{1}=1.432788 \\
d_{2}=0.189269 \\
d_{3}=0.001308
\end{gathered}
$$


The values of $\mathrm{c}_{0}, \mathrm{c}_{1}, \mathrm{c}_{2}, \mathrm{~d}_{1}, \mathrm{~d}_{2}, \mathrm{~d}_{3}$ given in Equation [12] are constants being widely employed for SPI computation (Abramowitz and Stegun, 1965).

\subsection{Assign drought level based on SPI} threshold

The SPI is a dimensionless index: When the values of SPI are negative, it indicates drought and vice versa, a positive sign indicates an excess of moisture.

In the world, SPI values were used to assess the drought level, with the drought classification thresholds as shown in Table 1 below

Table 1. Drought level using SPI (Edwards and McKee, 1997)

\begin{tabular}{cll}
\hline No. & SPI value & \multicolumn{1}{c}{ Drought level } \\
\hline 1 & $>2$ & Extremely moist \\
2 & 1.5 to 1.99 & Very moisture \\
3 & 1.0 to 1.49 & Moisture \\
4 & -0.99 to 0.99 & Normal \\
5 & -1.0 to 1.49 & Light drought \\
6 & -1.5 to 1.99 & Middle drought \\
7 & $<-2$ & Severe drought \\
\hline
\end{tabular}

Adapting to Vietnam condition, the drought level based on SPI index has been adjusted by the study of the Viet Nam institute of meteorology, hydrology and climate change (Tan and Huong, 2002). The adjusted SPI threshold for drought level is classified as shown in Table 2 below.

Table 2. Drought level by SPI (Tan and Huong, 2002)

\begin{tabular}{ccl}
\hline No & SPI value & \multicolumn{1}{c}{ Drought level } \\
\hline 1 & -0.49 to 0.25 & Start drought \\
2 & -0.99 to $-0,5$ & Middle drought \\
3 & -1.00 to -1.49 & Heavy drought \\
4 & -1.50 to -1.99 & Very heavy drought \\
5 & $\leq-2.00$ & Severe drought \\
\hline
\end{tabular}

\subsection{Database calculating and evaluating SPI index \\ - Based on the similarity of the location of the grid from the tool with the location of the rainfall station in NinhThuan province. \\ - Based on the existing rainfall data and the length of the calculation string of the tool, we}

choose to calculate the data series from 1981 to 2018 (456 months).

- Selected rainfall data was used for analysis including 3 stations: Phan Rang Station, Tan My Station and Quan The Station.

\subsection{Assessment of rainfall}

The effectiveness of the RDCYIS rainfall data will be verified by comparing extracted data from system with observations of selected stations. The parameters used in the verification process include: (1) average error (ME) representing the average error of the model over the observation, indicating the error bias of the model but not reflecting large magnitude of error - positive ME indicates higher predictive value than actual data and vice versa; (2) mean absolute error (MAE) is the mean of magnitude of error, not indicating the trend of error; (3) Mean squared error (MSE) measures the magnitude of errors, not indicating the trend of error; (4) The RMSE is the square root of the MSE and is a measure of the error amplitude but does not indicate the tendency of the error. The greater of RMSE means the variability be stronger.

Table 3. Correlation coefficient

\begin{tabular}{cc}
\hline Parameter & Formula \\
\hline Mean error & $M E=\frac{1}{n} \sum_{i=1}^{n}\left(S_{i}-G_{i}\right)$ \\
$\begin{array}{c}\text { Mean } \\
\text { absolute error }\end{array}$ & $M A E=\frac{1}{n} \sum_{i=1}^{n}\left|S_{i}-G_{i}\right|$ \\
\hline $\begin{array}{c}\text { Mean squared } \\
\text { error }\end{array}$ & $M S E=\frac{1}{n} \sum_{i=1}^{n}\left(S_{i}-G_{i}\right)^{2}$ \\
\hline $\begin{array}{c}\text { Root mean } \\
\text { squared error }\end{array}$ & $R M S E=\sqrt{\frac{1}{n} \sum_{i=1}^{n}\left(S_{i}-G_{i}\right)^{2}}$ \\
\hline $\begin{array}{c}\text { Pearson } \\
\text { correlation }\end{array}$ & $r=\frac{\sum_{i=1}^{n}\left(G_{i}-\bar{G}\right)\left(S_{i}-\bar{S}\right)}{\sqrt{\sum_{i=1}^{n}\left(G_{i}-\bar{G}\right)^{2} \sqrt{\sum_{i=1}^{n}\left(S_{i}-\bar{S}\right)^{2}}}}$
\end{tabular}

Therefore, if the RMSE is closer to MAE, the model error is more stable and the model product can be calibrated; (5) Pearson correlation coefficient ( $r$ ) indicates the degree of correlation between the two data sets, as value close to 1 demonstrate that the results of the model are consistent with the trend of the actual data. The formula for calculating the above indicators is 
shown in the Table 3.

\section{Results and discussion}

\subsection{Rainfall assessment}

Estimated values on the grid are extracted at midpoints with the coordinates of the selected stations including Phan Rang, Quan My, and
Tan My. In the Fig. 4, the graph of monthly observed and simulation precipitation shows the visual effectiveness of the model over time. Whereas the corresponding scattered graphs for each station show the correlation of actual values and predicted values - the more regression line approaching the $45^{\circ}$ angle, the closer the correlation. (a)

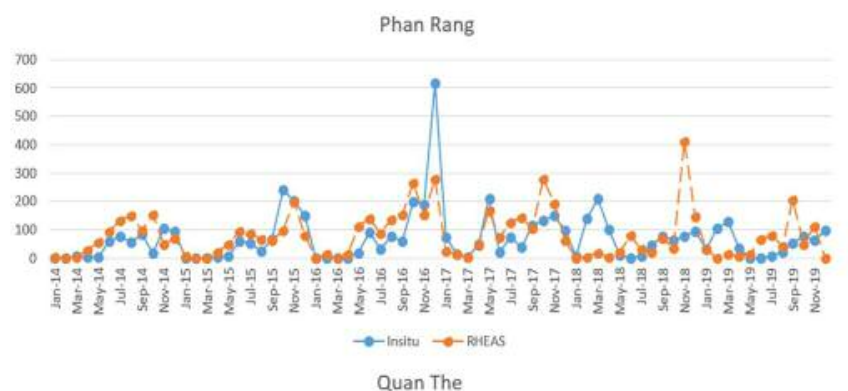

(b)

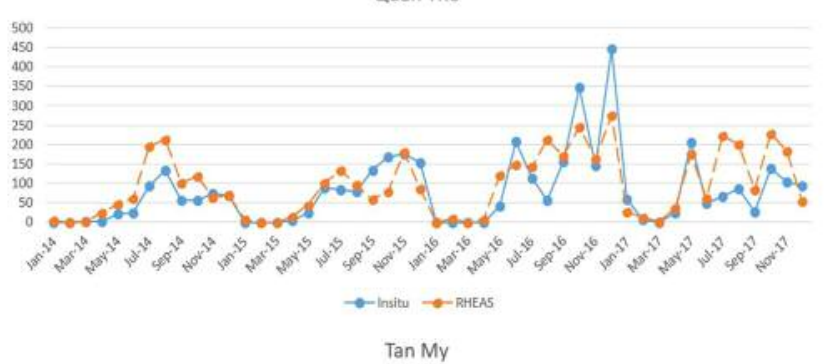

(c)

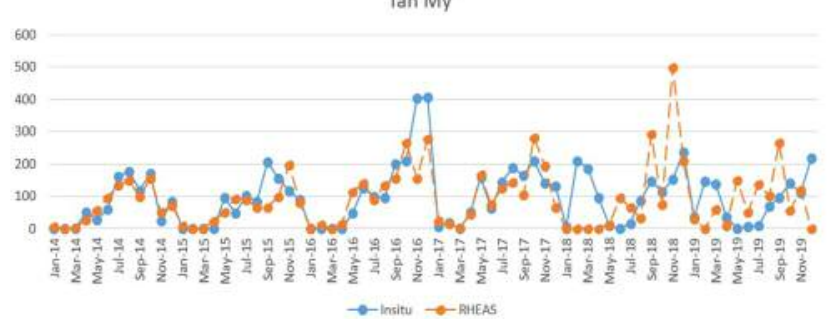

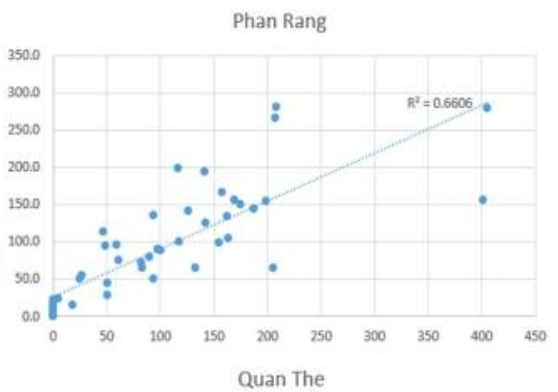
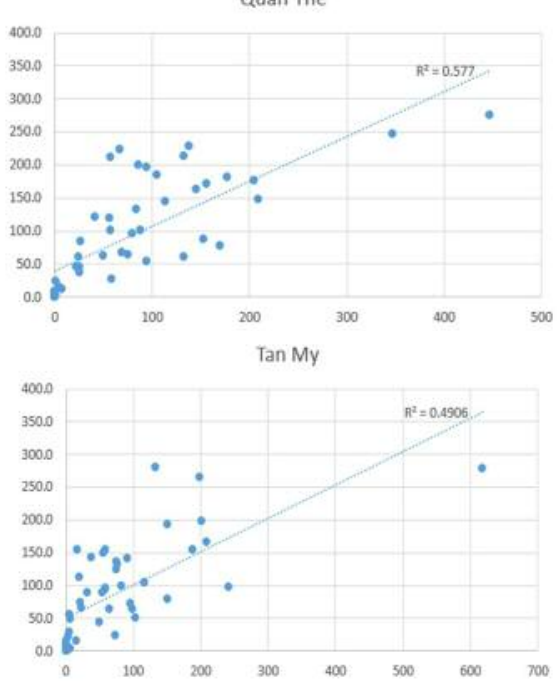

Fig. 4. Observed monthly rainfall and RCDYIS extracted rainfall: (a) Phan Rang station (20142019); (b) Quan The station (2014-2017); (c) Tan My station (2014-2019)

Through Fig. 4, it can be seen that the model has predicted relatively good monthly rainfall values. The model has quite well captured the trends of monthly rainfall trends according to selected stations, especially the peak of the actual rainfall graph is predicted by the prediction model. Seasonal distribution of rainfall is also well represented by rainfall patterns in the rainy season from June to December, while rainfall values in the remaining months are negligible. The correlation coefficient ranges from 0.49 to 0.66 as the value range applicable to the forecast data. However, the correlation coefficient between ground-truth data and simulation data also varies in each region of Ninh Thuan province. Specifically, the predicted value at Phan Rang station achieved the highest correlation coefficient of approximately 0.7 . On the other hand, the model usually presents a lower forecast in the winter months, i.e the rain value is expected to be smaller than the actual one. In contrast, in the summer months the regression model often produces high forecasts. The mean, absolute, squared error values are shown in the following table. Generally, the projection data are relatively good over the years and can therefore be used as inputs to the rainfall-runoff model for decision support. 
Application of SERVIR - Mekong's RDCYIS tool to enhance drought forecast and warning generation in Ninh Thuan province

Table 4. Result of Correlation coefficient by stations

\begin{tabular}{lcccc}
\hline \multicolumn{1}{c}{ Station } & ME & MAE & MSE & RMSE \\
\hline Phan Rang & -13.4 & 47.3 & 5538.56 & 74.42 \\
Quan The & -14 & 42 & 3770.8 & 61.4 \\
Tan My & 8.18 & 34.58 & 3091.52 & 55.6 \\
\hline
\end{tabular}

Analysis and evaluation of SPI index 1 month (Table 5 to Table 7) based on in-situ data of three locations in Ninh Thuan province:

Table 5 depicts SPI indicator analysis for Phan Rang station each month of the year based on the 1981-2018 period. It indicates that towards the end of the dry season (January to August), drought condition is severely increasing from normal condition to severe condition. Further, the severe drought condition will prevailed during the wet season (September to October). It can be seen that the amount of rainfall received during the wet season has significantly reduced and the severity of the dryness has also significantly increased.

Table 6 depicts SPI indicator analysis for Tan My station shows that towards the end of the dry season (January to August), drought condition is severely increasing from normal condition to se-

vere condition as depicted in Table 4. Further, the severe drought condition will privalile during the wet season (September to October) too. It can be seen that the amount of rainfall received during the wet season has significantly reduced in Tan My station and the severity of the dryness has also significantly increased.

Table 7 depicts SPI indicator analysis for Quan The station each month of the year based on the 1981-2018 period. It indicates that towards the end of the dry season (January to August), drought condition is severely increasing from normal condition to severe

conditions. Further, the severe drought condition will prevailed during the wet season (September to October) too. It can be seen that the amount of rainfall received during the wet season has significantly reduced and the severity of the dryness has also significantly increased.

Table 5. Number of days during each month with drought occurring at Phan Rang station

\begin{tabular}{lccccccccccccc}
\hline \multicolumn{1}{c}{ Drought level } & SPI & 1 & 2 & 3 & 4 & 5 & 6 & 7 & 8 & 9 & 10 & 11 & 12 \\
\hline Start drought & $-0.49 \div 0.25$ & 23 & 23 & 26 & 14 & 12 & 6 & 7 & 11 & 11 & 14 & 10 & 9 \\
Middle drought & $-0.99 \div-0,5$ & 0 & 0 & 0 & 0 & 0 & 0 & 0 & 0 & 0 & 0 & 0 & 0 \\
Heavy drought & $-1.00 \div-1.49$ & 0 & 0 & 0 & 0 & 3 & 3 & 4 & 2 & 4 & 3 & 5 & 7 \\
Very heavy drought & $-1.50 \div-1.99$ & 0 & 0 & 0 & 0 & 2 & 3 & 0 & 1 & 3 & 1 & 3 & 0 \\
Severe drought & $\leq-2.00$ & 0 & 0 & 0 & 0 & 0 & 1 & 2 & 2 & 0 & 2 & 0 & 0 \\
& Sum & 23 & 23 & 26 & 14 & 17 & 13 & 13 & 16 & 18 & 20 & 18 & 16
\end{tabular}

(Note: There are 217 drought months occurring out of a total of 456 months, accounting for $48 \%$ )

Table 6. Number of days during each month with drought occurring at Tan My station

\begin{tabular}{lcccccccccccccc}
\hline \multicolumn{1}{c}{ Drought level } & SPI & 1 & 2 & 3 & 4 & 5 & 6 & 7 & 8 & 9 & 10 & 11 & 12 \\
\hline Start drought & $-0.49 \div 0.25$ & 22 & 0 & 24 & 12 & 9 & 6 & 7 & 9 & 8 & 10 & 7 & 7 \\
Middle drought & $-0.99 \div-0,5$ & 0 & 0 & 0 & 0 & 0 & 0 & 0 & 0 & 0 & 0 & 0 & 0 \\
Heavy drought & $-1.00 \div-1.49$ & 0 & 0 & 0 & 0 & 3 & 2 & 5 & 1 & 4 & 3 & 5 & 5 \\
Very heavy drought & $-1.50 \div-1.99$ & 0 & 0 & 0 & 0 & 3 & 4 & 3 & 0 & 1 & 2 & 1 & 0 \\
Severe drought & $\leq-2.00$ & 0 & 0 & 0 & 0 & 0 & 1 & 2 & 2 & 0 & 2 & 0 & 0 \\
& Sum & 22 & 0 & 24 & 12 & 15 & 13 & 17 & 12 & 13 & 17 & 13 & 12 \\
\hline
\end{tabular}

(Note: There are 170 months with drought in total 456 months, accounting for 37\%) 
Dang Thanh Binh et al./Vietnam Journal of Hydrometeorology, 2020 (04): 67-75

Table 7. Number of days during each month with drought occurring at Quan The station

\begin{tabular}{lcccccccccccccc}
\hline \multicolumn{1}{c}{ Drought level } & SPI & 1 & 2 & 3 & 4 & 5 & 6 & 7 & 8 & 9 & 10 & 11 & 12 \\
\hline Start drought & $-0.49 \div 0.25$ & 22 & 0 & 24 & 12 & 9 & 6 & 7 & 9 & 8 & 10 & 7 & 7 \\
Middle drought & $-0.99 \div-0,5$ & 0 & 0 & 0 & 0 & 0 & 0 & 0 & 0 & 0 & 0 & 0 & 0 \\
Heavy drought & $-1.00 \div-1.49$ & 0 & 0 & 0 & 0 & 3 & 2 & 5 & 1 & 4 & 3 & 5 & 5 \\
Very heavy drought & $-1.50 \div-1.99$ & 0 & 0 & 0 & 0 & 3 & 4 & 3 & 0 & 1 & 2 & 1 & 0 \\
Severe drought & $\leq-2.00$ & 0 & 0 & 0 & 0 & 0 & 1 & 2 & 2 & 0 & 2 & 0 & 0 \\
& Sum & 22 & 0 & 24 & 12 & 15 & 13 & 17 & 12 & 13 & 17 & 13 & 12 \\
\hline
\end{tabular}

(Note: There are 181 months with drought in total 456 months, accounting for 40\%)

Table 8. Forecast results of standard precipitation index (SPI-01 month) in Ninh Thuan

\begin{tabular}{cccccc}
\hline $\begin{array}{c}\text { The time of } \\
\text { forecast }\end{array}$ & Central & West & North & East & Southern \\
\hline 01.12 .2019 & -0.77 & -0.80 & -0.86 & -0.69 & -0.79 \\
01.01 .2020 & 0.14 & 0.14 & -0.18 & 0.31 & 0.31 \\
01.02 .2020 & -1.24 & -1.25 & -1.30 & -1.19 & -1.19 \\
01.03 .2020 & 3.03 & -1.32 & 2.16 & 3.09 & 3.09 \\
01.04 .2020 & -1.63 & -1.27 & -1.63 & -1.58 & -1.62 \\
01.05 .2020 & -1.00 & -1.04 & -0.99 & -1.05 & -0.98 \\
01.06 .2020 & 0.19 & 0.21 & 0.23 & 0.15 & 0.21 \\
\hline
\end{tabular}

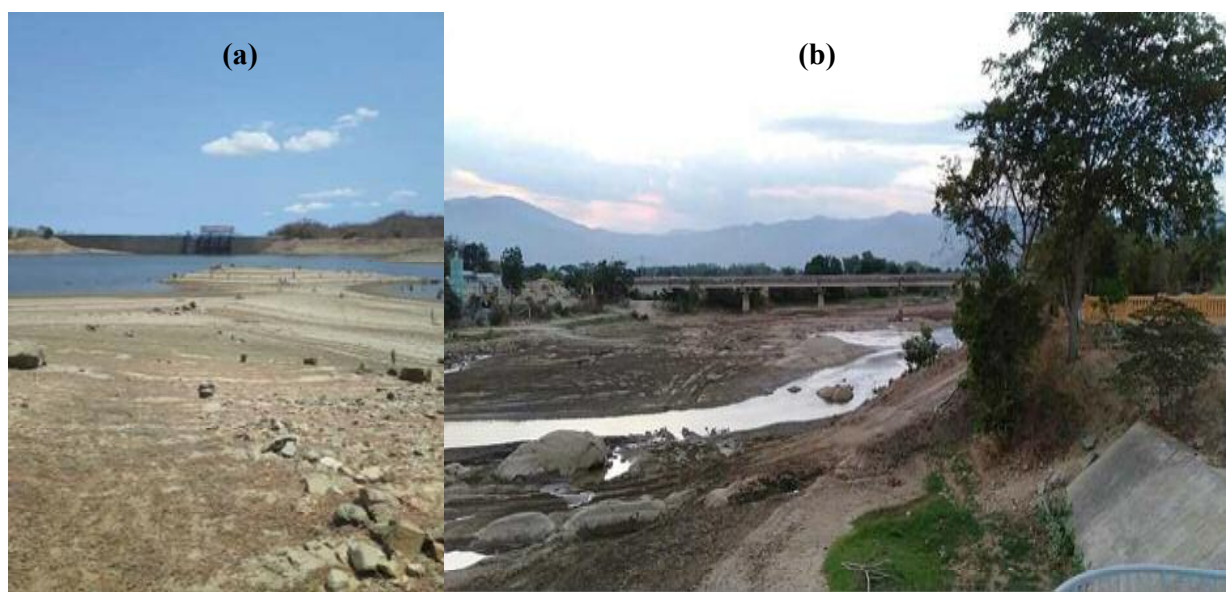

Fig. 5. Drought occurance in early 2020: (a) Under dead level of Tan Giang reservoir; (b) Lowflow of Cai River at Tan My Hydrological station

\section{Conclusions}

Using standard precipitation index (SPI) to calculate drought assessment is appropriate under current conditions and the actual drought situation in Ninh Thuan. Currently, due to the technology to forecast rain by multi-satellite combination, the results are quite good, the determination of the past rainfall at any location is convenient, overcoming the disadvantage of the lack of rain measuring station in the past.
In Ninh Thuan, the terrain is complex and divided into different climatic sub-regions, while there are only data for less than 30 years of only one meteorological station, so the use of other indicators has related to meteorological factors, which put into practice calculations for sub-regions will not reflect the actual situation. Climatic data used in the previous study on drought in Ninh Thuan was only statistics collected in some rainfall stations and only 01 meteorological station. Theerefore, drought forecast and 
warning information and its spatial variation was also assessed by regression method.

The research and putting into use of RDCYIS tool of SERVIR Mekong serves for forecasting and warning of drought natural disasters, in particular, can support the establishment of a plan to forecast and warn against drought natural disasters in the locality. Ninh Thuan Province is a convenient and effective solution.

Through effective research and application cooperation, the successful RDCYIS tool in Ninh Thuan will create a premise for SERVIR Mekong project to develop and upgrade the system, especially increasing the bandwidth from $25 \mathrm{~km}$ to $05 \mathrm{~km}$ in time and the expansion of the project space to the remaining provinces in the South Central region.

\section{Acknowledgments}

We thank Meteorology and Hydrological center in south central region, Ninh Thuan Meteorology and Hydrological center, Viet Nam Academy of Water Resources, ADPC and SERVIR-Mekong program for supporting our efforts in providing tool, data, and support analysis in this study.

\section{References}

1. Abramowitz, M., Stegun, A., 1965. Handbook of Mathematical Formulas, Graphs, and
Mathematical Tables. Dover Publications. Inc.

2. Binh, D.T., 2016. Assessing the impact of water shortage on agricultural production in Ninh Thuan. Water and Employment Conference.

3. Edwards, D.C., McKee, T.B., 1997. Characteristics of $20^{\text {th }}$ century drought in the United States at multiple scales. Atmospheric Science, 634, 1-30.

4. Ninh Thuan Hydro-met centre. 2019a. Observed daily waterlevel data by hydrological stations in Ninh Thuan.

5. Ninh Thuan Hydro-met centre. 2019b. Oserved daily rainfall data by stations in Ninh Thuan from 1981 - 2018.

6. Ninh Thuan IMC. 2019. Observed reservoirs's daily waterlevel data.

7. Sam, L., 2008. Research and assess the situation of drought, water shortage in the dry season, develop warning plans, and drought zoning maps in Ninh Thuan province. Southern Institute of Irrigation Science.

8. Sam, L., Vuong, N.D., 2008. Situation of drought, desertification in Ninh Thuan, causes, and solutions. Provincial project Southern Institute of Irrigation Science.

9. Tan, P.T., Huong, P.T.T., 2002. Modeling and testing drought forecast basing on the results of ENSO-drought relationship research in Vietnam. Institute of Meteorology and Hydrology. 